FACTA UNIVERSITATIS

Series: Mechanical Engineering Vol. 17, N ${ }^{\mathrm{o}} 1,2019$, pp. 17 - 27

https://doi.org/10.22190/FUME190104013P

Original scientific paper

\title{
TIRE WEAR PARTICLE HOT SPOTS - REVIEW OF INFLUENCING FACTORS
}

\section{Roman Pohrt}

Technische Universität Berlin, Germany

\begin{abstract}
Automotive tires have played an important role in land-based transportation and will probably continue to do so for many years to come. During their service lifetime, parts of the outer protector layer are worn off and discarded into the environment. A typical passenger car emits about 120 micrograms of rubber per meter but the exact current value depends on a multitude of influencing factors and varies greatly. We review available data on the wear rate (or inverse expected lifetime) of automotive rubber tires and extract qualitative estimations on how the most important parameters alter the deposition rate on a given road section. Local hot spots of increased tire wear particle occurrence can be identified from these parameters. It is concluded that generally subjecting tires to milder usage conditions can reduce tire wear by substantial amounts. Reducing vehicle speeds is identified as the most effective general measure.
\end{abstract}

Key Words: Tire, Wear rate, Road Particles, Non-exhaust Emissions, Hot-spots

\section{INTRODUCTION}

Transportation on land has relied on the use of rubber tires for many years. Being the component of the vehicle that is actually in contact with the ground, the tires support the vehicle weight and transfer loads such as lateral or horizontal accelerations. The number of passenger cars in the world was 1.02 billion in 2016 and is expected to reach 1.3 billion by 2024 [1].

In recent years, the focus of scientific research has shifted away from the emission directly related to the internal combustion. Instead, the so called non-exhaust-emissions have gained increasing attention [2-6]. This shift of focus is sensible because with increasing electrification of traffic, these emissions will remain relevant [7].

Part of the non-exhaust-emissions is the particles generated from the wear of the tires and the road. Because of their comparably large size, most of the particles emitted are not

Received January 04, 2019 / Accepted March 16, 2019

Corresponding author: Roman Pohrt

Technische Universität Berlin, Sekr. C8-4, Straße des 17. Juni 135, 10623 Berlin, Germany

E-mail: roman.pohrt@tu-berlin.de 
airborne. Instead, the particles are transported to the side of the road where they enter the soil or they are washed away with rain, either entering surface waters or going to waste water treatment, depending on the sewage water system [8, 9]. Thus, one possible approach to reducing the emission of wear particles from tires is to devise local collection systems in the sewage drains using filters that can be cleaned at regular intervals. However, some knowledge about the local emission rate from traffic is required.

Average emission rates are often obtained when testing the product life span of tires. Such test can be found in academic context as well as in consumer magazines. However, most such tests provide an emission rate for a specific vehicle and a specific tire, averaged over a given course. Momentary emission rate W (expressed in $\mu \mathrm{g} / \mathrm{m}$ ) of that tire during the course is likely to vary far more than different tires vary over the same course. We are instead interested in obtaining the deposition rate at a specific road section, averaged over an ensemble of vehicles that have passed this section.

The following review paper aims at giving qualitative dependencies that allow comparing the amount of emitted tire wear particles between different road sections. We define deposition rate $\mathrm{D}$ in $\mu \mathrm{g} /(\mathrm{m} \cdot \mathrm{d})$ as the mass of tread material that all passing vehicles have lost during one day per meter road length.

The following approach will be taken. As a base comparable value, we will compile available data on the dependency of the momentary wear rate of a passenger car from literature. This data can be taken from dedicated test drives, laboratory test benches or will be deduced from rough calculations of the vehicle forces. For vehicles other than passenger cars, it will be assumed that the qualitative dependencies on properties of the road section will remain the same and the wear rate will only differ by a constant factor. This approach deliberately excludes many influencing factors that alter the wear rate of any specific vehicle, some of which are discussed in Section 3.5.

\section{PARTICLES OF TIRE WEAR}

Tread rubber of tires is emitted in the form of elongated particles. In real life, these particles do not consist of pure tread material but are instead a mixture including wear particles from the road and possibly from other sources. Therefore, the particles found on roadsides are usually referred to as Tire and Road Wear particles (TRWP) and contain a multitude of materials stemming from other traffic-related or environmental sources [10]. The identification of particles as being TRWP is not trivial and still subject of current research [11, 12]. Different chemical markers and procedures have been applied [13]. Recently a standard was given to measure TWRP concentrations based on the PyrolysisGC/MS method [14].

Most studies agree that only $0.55 \ldots 10 \%$ [12] of particle mass is below $10 \mu \mathrm{m}$. Instead the characteristic size is in the order of $65-80 \mu \mathrm{m}[15,16]$ and does not get airborne $[17$, 18]. Fig. 1 shows typical particles. See [19] for a recent review on TRWP research. Because the aim of this study is to give only quantitative relations, we will focus solely on wear rate $\mathrm{W}$ defined as the amount of tread material removed from the vehicle per unit road length travelled. The resulting amount of TRWP will be higher because of additional material encrusted. 

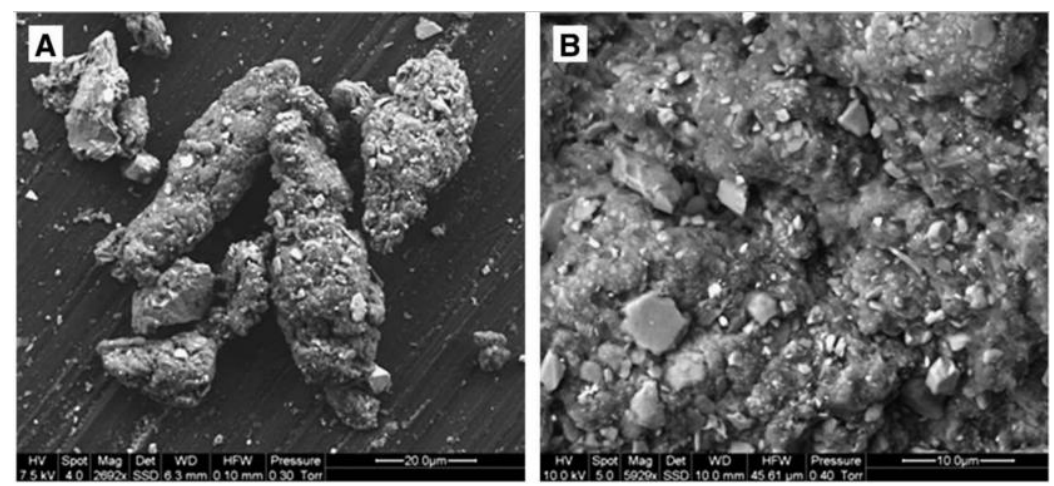

Fig. 1 REM images of Tire and road wear particles, from [20]

\section{WEAR RATES OF AUTOMOTIVE TIRES}

The wear rate of an automotive tire is the amount of mass lost $(\Delta m)$ per distance covered $(d)$ and is given in $[\mu \mathrm{g} / \mathrm{m}]$.

$$
W=\frac{\Delta m}{d} .
$$

During its service life, a typical modern tire of the passenger car loses around $\Delta m=1.4 \mathrm{~kg}$ of mass within approximately $d=50000 \mathrm{~km}$. The typical overall wear rate of the passenger car (with 4 tires) is, therefore, approximately $112 \mu \mathrm{g} / \mathrm{m}$. See [6,9] for an extensive discussion of this average value.

However, wear rate $W$ of a tire is a momentary quantity for a specific tire or vehicle in a specific driving situation and varies greatly over time.

Because no measurement technology is available to capture the wear rate directly on the vehicle during operation, researchers rely on measuring the remaining mass of the tire after a certain operational duration. Depending on the influencing factor in question, the following tests can be performed:

- Vehicle tests use actual cars driving either on public roads or test facilities. The course covered is recorded and used to calculate $\mathrm{W}$ based on distance. This type of test is very useful for distinguishing $\mathrm{W}$ for different cars, but data for specific driving situations is rarely available because the cars are usually used in a multitude of manoeuvres before the measurement (averaging) takes place. See [2123] for examples of such tests.

- Bench tests use single tires in a specially designed test machine that emulates driving. The bench test can either be a wheel-in-a-drum [24, 25] or carousel configuration [26]. Often times, the tire load and torque as well as the steering angle can be controlled. See [27, 28] for examples of such tests. The advantage of such tests is that very specific situations of tire loading can be investigated.

- Model tests do not use actual tires but employ the test machine with small rubber samples rolling on a rough counterpart surface. These tests are inexpensive; they allow for parameter studies and are often used to compare chemical compositions 
of the tread material. Different machines have been designed to fit special purposes [29, 30] but the most common test rig was developed by Grosch. See [31] for a description of the machine and results.

\subsection{Traffic profile}

The intensity and type of traffic that circulates on a given road have a direct influence on $D$. It is reasonable to assume that individual emissions from all vehicles will sum up to give the total deposition. The simplest approach is to assume a constant emission rate (such as the above-mentioned 112 micrograms $/ \mathrm{km}$ ) multiplied by the number of vehicles during a day.

When the vehicles are categorized according to their weight, the deposition rate can be calculated as

$$
D=\sum_{i} n_{i} W_{i}
$$

where $n_{i}$ is the number of vehicles from category $i$ per day and $W_{i}$ is the average emission rate for that category. Regrettably, literature on $W_{i}$ for vehicles other than passenger cars is scarce. Average values of 107 - 1500 micrograms/m per lorry alone are listed [32]. This scattering is in part due to a great variety of vehicle types and their configurations.

In a rare investigation, Gebbe et al. [22] measured the profile depth of tires and calculated the wear rates for a large number of vehicles in Berlin. Fig. 2 shows the average wear rates of vehicles within different ranges of maximum admissible vehicle weight $M$.

Please note that these values should be used carefully because they represent urban traffic. For instance, the wear rate of a city bus can be significantly different from a longdistance coach. If the central value in each category is considered, then the correlation is almost linear. This is consistent with [7, 33, 34]. A rough approximation can be given as

$$
W=\frac{M}{3.67 \cdot 10^{10} \mathrm{~m}} \text {. }
$$

Equations (3) and (2) can be used to take into account the influence of traffic intensity and its distribution over different categories of vehicles.

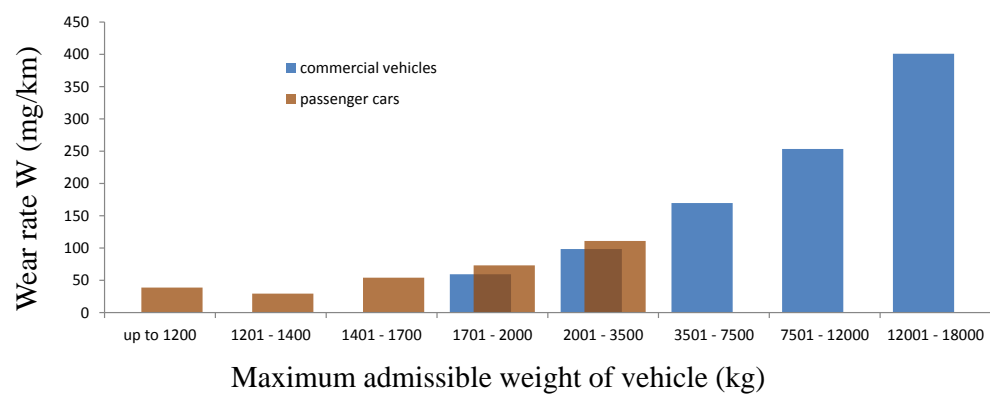

Fig. 2 Experimentally obtained mean values for wear rates of vehicles as a function of the maximum admissible weight. Data taken from Gebbe et al. [22] 


\subsection{Influence of characteristic vehicle manoeuvres}

Lengthwise load

When driving on straight roads, the car tires must overcome the resistive force directed backwards. $F_{\text {resist }}$ consists of multiple parts [23] which can be estimated for a given road section based on the likely vehicle operation and as a function of vehicle weight.

The inertia force applies to the road sections where vehicles are likely to stop and accelerate (e.g. traffic lights). An average force of

$$
F_{\text {inertia }}= \pm 1.4 \mathrm{~m} / \mathrm{s}^{2} \cdot M
$$

is a good estimate for normal operation, where $\mathrm{M}$ is the mass of the vehicle. The negative sign represents braking.

The slope force applies to inclined roads. Angle $\alpha$ is positive for uphill driving and the resulting force simply reads

$$
F_{\text {slope }}=9.81 \mathrm{~m} / \mathrm{s}^{2} \cdot \sin (\alpha) \cdot M
$$

The rolling resistance of the passenger car tires increases with speed. For low to medium speeds, it is approximately $1.3 \%$ of the vehicles gravitational force, so

$$
F_{\text {roll }}=0.13 \mathrm{~m} / \mathrm{s}^{2} \cdot M
$$

is a good estimate [35]. At very high speeds, this value can be more than twice as high. However, the most relevant force at high speeds is the aerodynamic drag force of the vehicle, which is given by

$$
F_{d r a g}=\frac{1}{2} \rho \cdot c_{w} \cdot A \cdot v^{2}
$$

Here $\rho=1.2 \mathrm{~kg} / \mathrm{m}^{3}$ is the density of air, $c_{w} \approx 0.4$ is the $\operatorname{drag}$ coefficient and $A$ is the face area of the vehicle.

The total resistive force, the sum of the four components, must be transferred by the vehicle's driven tires. A tire that is unloaded and rolling freely cannot transfer any forces. Only the combination of normal load to the surface and a certain amount of slip enables this. The horizontal slip is defined as difference of the rotational speed of the tire surface and the actual vehicle speed. If an identical unloaded tire $B$ is placed next to the loaded tire A, then slip $s$ can be calculated from the revolutions per minute (rpm) of the tires

$$
s=\frac{r p m_{B}-r p m_{A}}{r p m_{B}}
$$

The traction (defined as the horizontal force divided by the load) generated by a tire generally depends on the slip as shown in Fig. 3. Normal operation of vehicles takes place in the region of $s=1 \ldots 3 \%$, where the relation is linear. The maximum traction is attained for $s \approx 15 \ldots 20 \%$. 


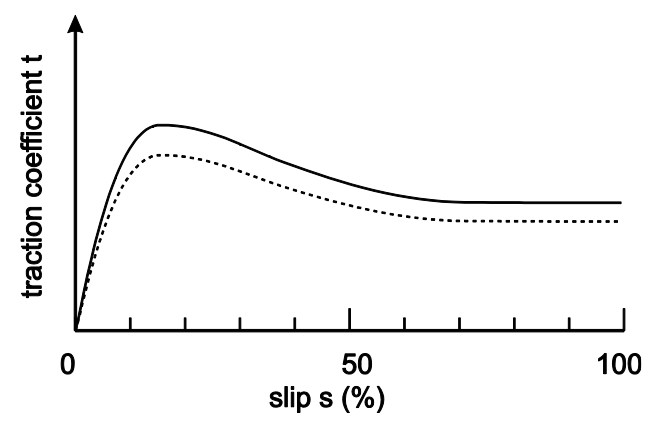

Fig. 3 Dependency of the tire traction on the slip (reproduced from [35])

At increasing vehicle speeds, the traction is decreased for all values of $s$, as shown with the dotted curves. The same is true for wet surfaces.

For almost all road surfaces at low slip rates, the wear rate is proportional to the square of the transmitted force or the slip respectively $[35,36]$. For this reason, the total resistive force should be squared to give a qualitative understanding of the local wear rate

$$
W \propto K_{\text {lengthwise }} F_{\text {resist }}^{2},
$$

where $K_{\text {lengthwise }}$ (unit $\mu \mathrm{g} \cdot \mathrm{m}^{-1} \cdot \mathrm{N}^{-2}$ ) is a constant factor. Table 1 lists the characteristic sum of forces squared for different road sections for a passenger car weighing $M=1400 \mathrm{~kg}$ and having face area $A \approx 2 \mathrm{~m}^{2}$.

Table 1 Values of the resistive force squared for selected road scenarios in $\mathrm{kN}^{2}$

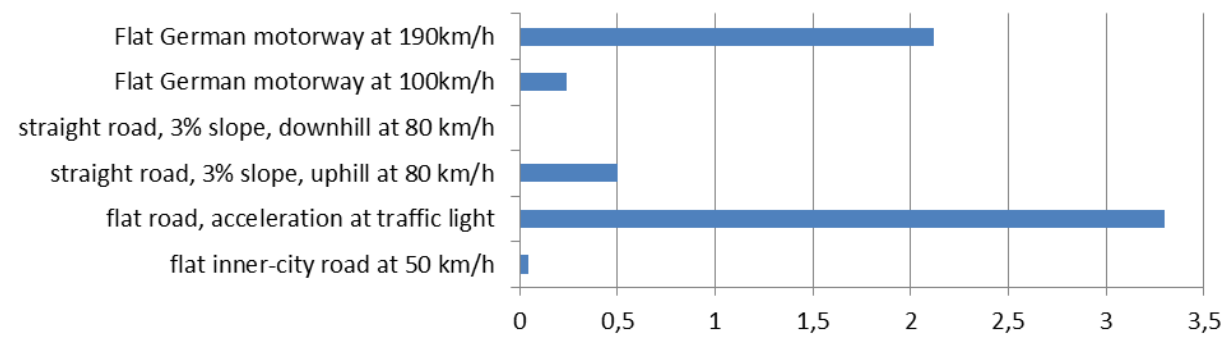

The greatest wear rate is thus to be expected in the short sections where vehicles must come to a stop. Considerable values are also to be expected on motorways with very high speeds. The latter case is due to the fact that the drag resistance effectively includes the vehicle speed with power four.

Please note: you may find a significantly weaker dependency on the rolling speed in some studies [37], but these do not consider the increased drag resistive force. Some studies also report a negative correlation between mean trip speed and tire wear rate, meaning that slower driving cars experience more tire wear than faster driving cars [6, 38, 39]. In all cases known to the authors, this is due to the hidden variable of driving in an urban environment (slow but more cornering and acceleration) vs. driving long distance trips. 


\section{Lateral load}

Similar to the lengthwise direction, a rolling tire cannot transfer lateral forces without experiencing a certain amount of slip. This is realized by imposing a certain slip angle defined as the angle between the direction in which the tire is pointing and the direction in which it is actually travelling. The slip angle in normal driving situations is $\beta=-3^{\circ} \ldots 3^{\circ}$. For a turning manoeuvre at speed $v$ and radius or curvature $R$, centripetal force $F_{\text {cent }}$ reads

$$
F_{c e n t}=M \frac{v^{2}}{R} \text {. }
$$

In addition to the centripetal force, there is the force related to the cross slope of the road, $F_{c s}$. Let $\alpha$ be the angle of the cross slope (positive for banked turn)

$$
F_{c s}=9.81 \mathrm{~m} / \mathrm{s}^{2} \cdot \sin \left(\alpha_{c s}\right) \cdot M
$$

The total lateral force to be carried by the tires reads

$$
F_{\text {lateral }}=F_{\text {cent }}-F_{c s} \text {. }
$$

The dependency between $\beta$ and $F_{\text {lat }}$ is nonlinear [35, 40, 41]. Determining experimentally the wear rate as a function of $\beta$ or $F_{\text {lateral }}$ for a real tire is not trivial because great care must be taken not to overstress it thermally. For instance, Lupker et al. [42] had to discard multiple truck tires that were subjected permanently to $\beta=0.2^{\circ}$, because these would wear intensively and in an unrealistic fashion. For the influence on wear rate $W$, [36] reports a quadratic dependency similar to Eq. (9):

$$
W \propto K_{\text {lateral }} F_{\text {lateral }}^{2}
$$

This is consistent with [40] and with the nonlinear dependency found in [43] against abrasive paper. Veith [44] adds that despite of the similar dependency, lateral forces lead to a significantly higher wear rates, translating into $\mathrm{K}_{\text {lateral }} \approx 7 \mathrm{~K}_{\text {lengthwise. }}$ Table 2 lists some values for the square of the centripetal force in different road sections. In contrast to Table 1 , these values are closer to each other, which is not surprising. Drivers tend to choose their cornering speeds so that the centripetal acceleration is at an acceptable level for both driver and vehicle.

Table 2 Values of the centripetal force squared for selected road scenarios in $\mathrm{kN}^{2}$

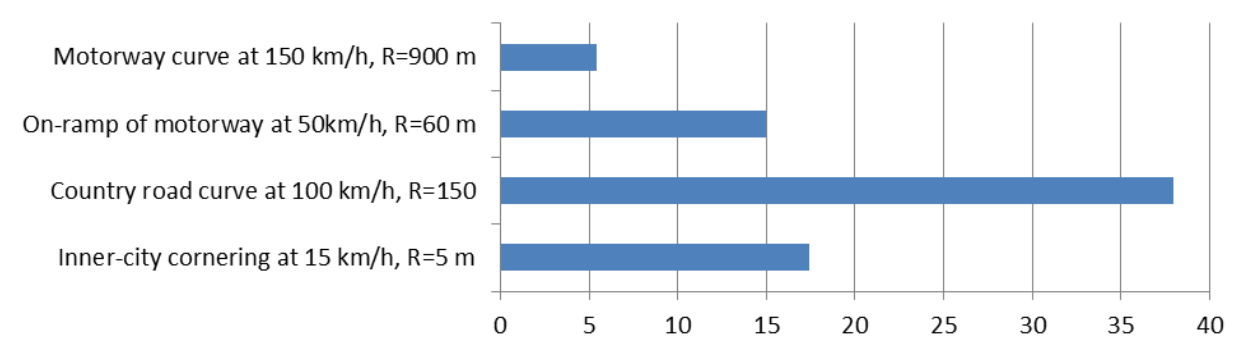


The values obtained for lateral load are all much higher than those for lengthwise load. It can be concluded that most of the tire wear happens during cornering and that cornering section of roads are most likely to accumulate high quantities of tire wear particles. This is in agreement with [36] and with the bench test results of [38] where simulated city driving accounted for $63 \%$ of the tire wear, although it accounted for only $5 \%$ of the distance driven, the rest being a motorway scenario.

\subsection{Influence of road surface}

The road surface and in particular its texture influence the wear rate. In an extreme case, [21] reports $W$ to increase by more 10 times on the German Nürburgring course compared to concrete/asphalt roads at the same speed.

Most of European and American road surfaces consist of open asphalt. It has 15-25\% hollow space which can retain wear particles [9]. Asphalt roads with varying density were tested in [26, 45] and it was found that lower-density asphalt had a higher wear rate. Authors assume this was due to the well maintained microstructure of this type. Asphalt roads are also found to have higher rolling resistance [23] and higher wear rate than concrete roads [46]. Because asphalt is an aggregate of particles with a bitumen binder, a distinction between the macro texture (size, distribution and geometrical configuration of particles) and the micro texture (of the individual particles) can be made. With the wearing away of the bitumen binder and the resulting increase of surface voids, the macro texture tends to increase over time. In contrast, the micro texture tends to diminish due to polishing [36]. In an extensive test using a series of test pavements, Lowne [47] showed that the roughness of the micro texture is the main driver to increased wear of a road surface, while the macro texture has minor influence.

\subsection{Seasonal changes}

Multiple studies investigate the influence of seasonal changes on vehicle wear rates but conclusions vary.

During the summer months, roads tend to have smaller micro texture and friction due to polishing compared to winter [36], which is generally associated with increased wear. Indeed, Le Maitre et al. [33] report a 1.6 to 1.7 - fold increase in wear rates during the winter season.

In contrast, it is found that wear rates increase by $1 \ldots 4 \%$ per ${ }^{\circ} \mathrm{C}$ increase in temperature [37, 48]. This appears to be confirmed by investigations from [21], where an increase of tire lifespan by $31 \%$ for passenger cars and $9 \%$ for commercial vehicles during the winter season was found.

\subsection{Other factors}

Because this study focuses on the amount wear deposited at any given road section, averaged over total traffic, influences on wear rate $\mathrm{W}$ that are vehicle-specific were not considered in detail. However, they may have great impact. Some of the main factors include

- exact brand/model: $\sim 4$ fold difference in $W[28]$

- tire geometry: wider tires have slightly lower $W[33]$

- tire age: new tires have $~ 10 \%$ higher $W[49]$ 
- balancing of wheels: imbalances cause increase in $W$ [21]

- tire pressure: lower pressure increases $W$ [21, 34, 37]

- temper of driver: 6.2 fold in $W$ between drivers on the same course [33], or 1.4 fold within the same convoy [21]

As a consequence, even identical vehicles with identical tires may have different average wear rates. In the study of Gebbe [22], authors identified 4 recurring passenger cars and 3 commercial vehicles with up to 20 units each and compared their wear rate. The ratio between minimum and maximum $\mathrm{W}$ was typically $1.3-2$ with the exception of Fiat Cinquecento vehicles at 3.7. Standard deviations were not given.

Studded tires are known to have greatly increased wear rates in the tire and the road [15]. They are excluded from this study. Because modern cars are equipped with powerassisted steering, it is common for drivers to steer the wheels when the vehicle is stationary, e.g. during inner-city parking manoeuvres. It is expected that these rare operations are particularly harmful to the tire but are excluded from this study.

Other limitations apply. The combination of different loading and varying surface topography and/or seasonal changes is not strictly linear. For instance, some road surfaces are known to alter the exponent in the force-vs.-wear equation (13) from 2 to 3 or higher values. Indeed, different approaches to give an overall severity rating exist $[44,50]$.

Due to the lack of available data for vehicles other than passenger cars, a constant factor can be used to characterize those. Even for passenger cars and their typical tires, reliable experimental date for specific loading is sparse. More experimental data on test benches is required that reproduces acceleration and cornering manoeuvres but does so with pausing intervals as not to overstress the tire thermally.

\section{DISCUSSION}

The main influencing factors on the estimated amount of tire wear deposition at any given road section have been reviewed. For an average passenger car, the rough dependencies are given in the corresponding sections and can be used in order to compare two otherwise identical road sections qualitatively. It is found that by far the greatest emission is to be expected at road section where changes of direction happen. Assuming that a particular term is most prominent in every case where an increased wear is observed, one can identify the most dominating quantities.

In curves without cross slope, measure $v^{4} R^{-2}$ (Eqs. (10) and (13)) is the most dominating quantity on a one-vehicle-basis. Here, wear can be reduced greatly by reducing local vehicle speeds because of the power four in the velocity dependence. For instance, lowering the allowed speed from $50 \mathrm{~km} / \mathrm{h}$ to $30 \mathrm{~km} / \mathrm{h}$ in a curve is expected to reduce tire wear emission down to $(3 / 5)^{4}=13 \%$ ! Another means is adding a suited cross slope to counteract the centripetal force.

At straight road sections, increased wear is only expected at stops or where vehicles travel at very high speeds. In the latter case, the speed again enters the amount of wear in power four (Eqs. (7) and (9)); therefore, a motorway speed limit can be an effective measure.

We conclude that road sections can differ in their expected deposition rate by orders of magnitude. Besides the obvious aspect of low vs. intense traffic, the surface type, the typical vehicle speed and the radius of curvature have a great influence. The relations 
given in the paper can be used to identify so called "hot spots" of elevated emission exposure for local counter-measures.

Acknowledgements: The paper is part of the research done within the project "Reifenabrieb in der Umwelt (RAU)", grant no. 13NKW011A of German ministry of education and research. The author would like to thank Dr. Rauterberg-Wulff for useful discussion and providing refs.[22,35].

\section{REFERENCES}

1. Cinaralp, F., 2017, ETRMA statistics report n.9, Technical report, European Tyre and Rubber Industry.

2. Kwak, J., Kim, H., Lee, J., Lee, S., 2013, Characterization of non-exhaust coarse and fine particles from onroad driving and laboratory measurements, Science of the Total Environment, 458-460, pp. 273-282.

3. Kwak, J., Lee, S., Lee, S., 2014, On-road and laboratory investigations on non-exhaust ultrafine particles from the interaction between the tire and road pavement under braking conditions, Atmospheric Environment, 97, pp. 195-205.

4. Grigoratos, T., Martini, G., 2014, Non-exhaust traffic related emissions. Brake and tyre wear PM, Technical report, European Commission Joint Research Centre Institute of Energy and Transport.

5. Essel, R., Engel, L., Carus, M., Ahrens, R.H., 2015, Sources of microplastics relevant to marine protection in Germany, Technical report, Umweltbundesamt.

6. Boulter, P., 2005, Trl report ppr065: A review of emission factors and models for road vehicle non-exhaust particulate matter, Technical report, TRL Limited.

7. Timmers, V.R., Achten, P.A., 2016, Review article: Non-exhaust PM emissions from electric vehicles, Atmospheric Environment, 134, pp. 10-17.

8. Fuchs, D.S., Scherer, D.U., Wander, R., Behrendt, D.H., Venohr, D.M., Opitz, D., Hillenbrand, D.T., Marscheider-Weidemann, D.F., Götz, T., 2010, Berechnung von Stoffeinträgen in die Fließgewässer Deutschlands mit dem Modell MONERIS, Technical report, Umweltbundesamt.

9. Kole, P.J., Löhr, A.J., Belleghem, F.G.A.J.V., Ragas, A.M.J., 2017, Wear and tear of tyres: A stealthy source of microplastics in the environment, Int. J. Environ. Res. Public Health, 14,1265, p. 31.

10. Dall'Osto, M., Beddows, D.C., Gietl, J.K., Olatunbosun, O.A., Yang, X., Harrison, R.M., 2014, Characteristics of tyre dust in polluted air: Studies by single particle mass spectrometry (atofms), Atmospheric Environment, 94, pp. 224-230

11. Gunawardana, C., Goonetilleke, A., Egodawatta, P., Dawes, L., Kokot, S., 2012, Source characterisation of road dust based on chemical and mineralogical composition, Chemosphere, 87, pp. 163-170.

12. Panko, J.M., Chu, J.A., Kreider, M.L., McAtee, B.L., Unice, K.M., 2012, Quantification of tire and road wear particles in the environment, Urban Transport, 128, pp. 59-70.

13. Sommer, F., Dietze, V., Baum, A., Sauer, J., Gilge, S., Maschowski, C., Gieré, R., 2018, Tire abrasion as a major source of microplastics in the environment, Aerosol and Air Quality Research, 18, pp. 2014-2028.

14. Iso/ts 21396:2017: Determination of mass concentration of tire and road wear particles (trwp) in soil and sediments.

15. Ntziachristos, L., Boulter, P., 2016, EMEP/EEA air pollutant emission inventory guidebook, European Environment Agency, chapter 1.A.3.b.vi Road transport: Automobile tyre and brake wear 1.A.3.b.vii Road transport: Automobile road abrasion.

16. Lee, S., Kwak, J., Kim, H., Lee, J., 2013, Properties of roadway particles from interaction between the tire and road pavement, International Journal of Automotive Technology, 14(1), pp. 163-173.

17. Mathissen, M., Scheer, V., Vogt, R., Benter, T., 2011, Investigation on the potential generation of ultrafine particles from the tire-road interface, Atmospheric Environment, 45, pp. 6172-6179.

18. Panko, J.M., Chu, J., Kreider, M.L., Unice, K.M., 2013, Measurement of airborne concentrations of tire and road wear particles in urban and rural areas of France, Japan, and the United States, Atmospheric Environment, 72, pp. 192-199.

19. Panko, J., Kreider, M., Unice, K., 2018, Non-Exhaust Emissions: An Urban Air Quality Problem for Public Health; Impact and Mitigation Measures, Academic Press, pp. 147-160.

20. Kreider, M.L., Panko, J.M., McAtee, B.L., Sweet, L.I., Finley, B.L., 2010, Physical and chemical characterization of tire-related particles: Comparison of particles generated using different methodologies, Science of the Total Environment, 408, pp. 652-659. 
21. Continental, ca. 1960, Einflüsse der Fahrpraxis auf die Lebensdauer von fahrzeugreifen - ein Versuchsbericht, Technical report, Continental Gummi-Werke Aktiengesellschaft Hannover.

22. Gebbe, Hartung, Berthold, 1998, Quantifizierung des Reifenabriebs von Kraftfahrzeugen in Berlin, Technical report, Institut für Straßen- und Schienenverkehr TU Berlin, studie im Auftrag der Senatsverwaltung für Stadtentwicklung, Umweltschutz und Technologie, Berlin.

23. Wilde, J., 2014, Rolling resistance measurements at the MnROAD facility, round 2, Technical report, Center for Transportation Research and Implementation Minnesota State University, Mankato.

24. Glaeser, K.P., Zöller, M., 2009, Innentrommelprüfstand (IPS), Technical report, Bundesanstalt für Straßenwesen.

25. Glaeser, K.P., Bartolomaeus, W., 2014, Prüfstand Fahrzeug/Fahrbahn, Technical report, Bundesanst. f. Straßenwesen.

26. Do, M.T., Kerzreho, J.P., Balay, J.M., Gothie, M., 2003, Full scale tests for the assessment of wear of pavement surfaces, TRB 82nd Annual Meeting (Transportation Research Board), Jan 2003, France.

27. Lupker, H., 2003, Tyre and road wear prediction, Technical report, TNO Automotive and TROWS consortium (9 partners from 5 EC countries).

28. Grigoratos, T., Gustafsson, M., Eriksson, O., Martini, G., 2018, Experimental investigation of tread wear and particle emission from tyres with different treadwear marking, Atmospheric Environment, 182, pp. 200-212.

29. Veith, A.G., 1973, Accelerated tire wear under controlled conditions. I. description of the test system, Rubber Chem. Technol., 46(4), pp. 801-820.

30. Vieira, T., Ferreira, R., Kuchiishi, A., Bernucci, L., Sinatora, A., 2015, Evaluation of friction mechanisms and wear rates on rubber tire materials by low-cost laboratory tests, wear, 328-329, pp. 556-562.

31. Grosch, K.A., 2008, Rubber abrasion and tire wear, Rubber Chemistry and Technology, 81(3), pp. 470-505.

32. Hillenbrand, T., Toussaint, D., Böhm, E., Fuchs, S., Scherer, U., Rudolphi, A., Hoffmann, M., 2005, Einträge von Kupfer, Zink und Blei in Gewässer und Böden - Analyse der Emissionspfade und möglicher Emissionsminderungsmaßnahmen, Technical Report Bericht 20224220/02, Umweltbundesamt.

33. Le Maître, O., Süssner, M., Zarak, C., 1998, Evaluation of tire wear performance, SAE Technical Papers: International Congress and Exposition, Detroit, Michigan, February 23-26.

34. Wang, C., Huang, H., Chen, X., Liu, J., 2017, The influence of the contact features on the tyre wear in steadystate conditions, Proc IMechE Part D: J. Automobile Engineering, 231(10), pp. 1326-1339.

35. Scholz, G.H., 1994, Wie lange lebt ein Reifen?, Reifentechnische Informationen, volume 3, Gummiwerke Fulda.

36. Veith, A.G., 1992, A review of important factors affecting treadwear, Rubber Chem. Technol., 63(3), pp. 601658.

37. Li, Y., Zuo, S., Lei, L., Yang, X., Wu, X., 2011, Analysis of impact factors of tire wear, Journal of Vibration and Control, 18(6), pp. 833-840.

38. Stalnaker, D., Turner, J., Parekh, D., Whittle, B., Norton, R., 1996, Indoor simulation of tire wear: Some case studies, Tire Science and Technology, 24(2), pp. 94-116.

39. Luhana, L., Sokhi, R., Warner, L., Mao, H., Boulter, P., McCrae, I., Wright, J., Osborn, D., 2004, Characterisation of exhaust particulate emissions from road vehicles; Deliverable 8: Measurement of nonexhaust particulate matter, Technical report, EU Particulates of Fifth Framework Programme.

40. Chen, X., Xu, N., Guo, K., 2018, Tire wear estimation based on nonlinear lateral dynamic of multi-axle steering vehicle, International Journal of Automotive Technology, 19(1), pp. 63-75.

41. Leister, G., 2009, Fahrzeugreifen und Fahrwerkentwicklung, ATZ/MTZ-Fachbuch.

42. Lupker, H., Montanaro, F., Donadio, D., Gelosa, E., Vis, M., 2002, Truck tyre wear assessment and prediction, 7th International Symposium on Heavv Vehicle Weights \& Dimensions, Delft.

43. Park, I., Kim, H., Lee, S., 2018, Characteristics of tire wear particles generated in a laboratory simulation of tire/road contact conditions, Journal of Aerosol Science, 124, pp. 30-40.

44. Veith, A.G., 1973, Accelerated tire wear under controlled conditions. II. some factors that influence tire wear, Rubber Chem. Technol., 46(4), pp. 821-842.

45. Gothie, M., Do, M.T., 2003, Road polishing assessment methodology 'TROWS', XXIIth PIARC World Road Congress, Oct 2003, South Africa.

46. Pant, P., Harrison, R.M., 2013, Estimation of the contribution of road traffic emissions to particulate matter concentrations from field measurements - a review, Atmospheric Environment, 77, pp. 78-97.

47. Lowne, R.W., 1971, The effect of road surface texture on tire wear, Rubber Chem. Technol., 44(5), pp. 11591172 .

48. Grosch, K.A., Schallamach, A., 1961, Tyre wear at controlled slip, Wear, 4(5), pp. 356-371.

49. Sakai, H., 1996, Friction and wear of tire tread rubber, Tire Science and Technology, 24(3), pp. 252-275.

50. Lupker, H., Cheli, F., Braghin, F., Gelosa, E., Keckman, A., 2004, Numerical prediction of car tire wear, Tire Science and Technology, 32(3), pp. 164-186. 